\title{
Persistence of travel and leisure sector equity indices
}

\author{
Jorge M. L. Andraz ${ }^{1}\left[\right.$ Raúl F. C. Guerreiro $^{2}(\mathbb{D} \cdot$ \\ Paulo M. M. Rodrigues ${ }^{3}$ (1)
}

Received: 5 October 2015 / Accepted: 4 April 2017 / Published online: 1 July 2017

(C) Springer-Verlag GmbH Germany 2017

\begin{abstract}
Volatility persistence of travel and leisure sector equity indices and of some of its components is analyzed, and tests of whether persistence has changed over time are performed. Given the typical leading indicator behavior of financial variables, understanding and characterizing the properties of these indices may help shed light on the behavior of the tourism sector and of its resilience to crises. For the purpose of analysis, our sample is split into three subsamples according to the World tourism cycle: (i) from January 1996 to December 2002; (ii) from January 2003 to August 2007; and (iii) from September 2007 to July 2014. Results suggest the existence of long-memory dynamics driving series volatility, and that shocks to volatility tend to be more persistent during periods of turmoil and affect regions differently.
\end{abstract}

Keywords Long memory $\cdot$ Persistence breaks $\cdot$ Crises $\cdot$ Tourism

JEL Classification $\mathrm{C} 22 \cdot \mathrm{G} 21 \cdot \mathrm{G} 32$

The first two authors are pleased to acknowledge financial support from Fundação para a Ciência e a Tecnologia (grant UID/ECO/04007/2013) and FEDER/COMPETE (POCI-01-0145-FEDER-007659).

$凶$ Jorge M. L. Andraz

jandraz@ualg.pt

1 Faculty of Economics, Universidade do Algarve and CEFAGE-Ualg, 8005-139 Faro, Portugal

2 ESGHT, Universidade do Algarve and CEFAGE-Ualg, Faro, Portugal

3 Banco de Portugal and Nova School of Business and Economics, Universidade Nova de Lisboa, Lisbon, Portugal 


\section{Introduction}

The tourism sector is of considerable importance for the overall economic development of many countries (see, inter alia, Eugenio-Martin et al. 2004; Andraz et al. 2009). Given its importance, it is of interest to analyze the volatility of the travel and leisure equity index returns and of its components in order to understand how businesses that operate in this sector have performed over time and how resilient the sector is to crisis.

Ding et al. (1993) documented the existence of long-range dependence in several transformations of the absolute value of daily returns, noting that these proxies of volatility exhibit slowly decaying autocorrelation functions. Granger and Ding (1996) found this form of persistence to be conformable with a long-memory process with characteristic coefficient $\widehat{d} \approx 0.47$. This evidence has been extended to realized volatility measures, for which the estimates of the fractionally integrated parameter also tend to lie around this value; see, for instance, Andersen et al. (2003) and Hassler et al. (2016). The recent literature on long memory has focused on the stability of the longmemory coefficient, reporting evidence suggesting that the degree of persistence may not be constant over time; see Kumar and Okimoto (2007), Bos et al. (2012), Martins and Rodrigues (2014), Hassler and Meller (2014) and Hassler et al. (2014).

In this paper, we implement procedures for fractional integration testing on the log of absolute returns of representative stock portfolios of the travel and leisure industry in different regions and economic areas of the world aiming to analyze whether the characteristic degree of persistence in the volatility of these series has remained stable or whether it has changed over the business cycle regimes and, in particular, as a consequence of the occurrence of different crisis. This issue, which is particularly relevant for both analysts and forecasters, has not been addressed in previous literature. While it is perfectly clear that the mean of the volatility process shifts as a consequence of crisis, it is possible that other characteristics of the data generating process, such as the degree of persistence, may change as well. Under extreme market circumstances, shocks on the variability of returns may become more persistent because investors become more risk-averse, an indication of market adversities. As a result, the longmemory parameter that characterizes the long-term dynamics of the volatility process of returns may take larger values and even exhibit non-stationary features. Using a sample that covers a period in which several crises have occurred, we look to contribute with further evidence on this issue, particularly from a sector which is of considerable economic importance, but to which little attention in this context seems to have been given.

To this end, we proceed as follows. We apply the regression-based test proposed by Breitung and Hassler (2002) and Demetrescu et al. (2008) [DKH henceforth] to detect long memory in several time series. The interest in this test results from the fact that it exhibits more power than alternative procedures while retaining a considerable degree of tractability and methodological simplicity. The experimental simulations in Tanaka (1999), Breitung and Hassler (2002) and Rodrigues et al. (2013) show that in finite samples the time domain tests tend to be superior to the frequency domain tests both in size and power behavior-a further argument in favor of the procedure just described. 
Additionally, we apply a simple test for the null hypothesis that the memory estimates of two non-overlapping subsamples are equal, which was recently introduced by Hassler et al. (2014) and that builds on an approach proposed by Shimotsu (2006). The test statistic follows asymptotically a standard normal distribution. Finally, we use this testing procedure and the DKH test to characterize the persistence of the log transform of daily absolute returns of travel and leisure equity indices and of several of its components (hotels, airlines, and tourism and travel) over different periods and for different regions and economic zones. Since our main interest lies in characterizing the effects on persistence of different episodes, we split the total sample into three disjoint periods following the world tourism cycle (which we extracted using a state space approach).

We provide confidence intervals for the order of integration based on the DKH procedure by inverting the range of values not rejected by the integration test as suggested in Hassler et al. (2009). We also report point estimates of d (the order of integration) using semi-parametric procedures and their corresponding confidence intervals and analyze the difference over the sub-periods. The overall evidence from this analysis suggests the existence of long memory dynamics driving the volatility of these series. However, the suitability of a model with constant parameter over the total period is generally rejected, showing that shocks in volatility tend to be more persistent during periods of turmoil. Although a common picture emerges, there are important differences among the different regions and economic areas considered. As expected, the effects of crisis are more pronounced in areas which were directly exposed to these events. This evidence is consistent with the hypothesis that long-range persistence may be linked to economic fundamentals (Hassler et al. 2014).

The rest of the paper is organized in three sections. The next section introduces the notion of fractionally integrated process, the regression framework of DKH and the test for the null hypothesis that non-overlapping subsamples are integrated of the same order. The following section presents the data, an overview of the main events that impacted tourism and introduces the results of our empirical analysis. The final section summarizes the main findings of the paper.

\section{Methodology}

To introduce the methodology used in the analysis below, consider a stationary fractionally integrated process, i.e., an $I\left(d_{0}\right)$ process, with parameter $-1 / 2<d_{0}<1 / 2$ such as,

$$
y_{t}=\mu+(1-L)^{-d_{0}} \varepsilon_{t}, \quad(1-L)^{-d_{0}}:=\sum_{j=0}^{\infty}\left(\begin{array}{c}
-d_{0} \\
j
\end{array}\right)(-L)^{j}, t=1, \ldots, T
$$

where $\mu<\infty$ is the expected value of the process, $L$ is the usual lag operator, $L_{t}^{j} \varepsilon=\varepsilon_{t-j}$, and $\left\{\varepsilon_{t}\right\}$ is a covariance stationary process whose spectral density is bounded and bounded away from zero at the origin. The distinctive feature of fractionally integrated processes when compared to conventional integrated processes is that the coefficient $d_{0}$ is allowed to take non-integer values. When $\left\{\varepsilon_{t}\right\}$ verifies suitable 
conditions, $\left\{y_{t}\right\}$ admits the Wold decomposition $y_{t}=\mu+\sum_{j=0}^{\infty} \psi_{j}\left(d_{0}\right) \varepsilon_{t-j}$ with impulse response coefficients $\left\{\psi_{j}\left(d_{0}\right)\right\}$ dying out hyperbolically at rate $j^{d_{0}-1}$; for necessary and sufficient conditions on $\left\{x_{t}\right\}$ for such a behavior to hold see Hassler and Kokoszka (2010, Prop. 2.1). For $d_{0}<0.5, \sum_{j=0}^{\infty}\left[\psi_{j}\left(d_{0}\right)\right]^{2}<\infty$, i.e., the sequence $\left\{\psi_{j}\left(d_{0}\right)\right\}_{j \geq 0}$ is square summable and, therefore, $\left\{y_{t}\right\}$ is a stationary process. Nevertheless, the sequence is not absolutely summable when $d_{0}>0$, which gives rise to long memory. The larger the order of integration $d_{0}$, the slower $\psi_{j}\left(d_{0}\right)$ dies out, such that $d_{0}$ measures the degree of memory (persistence) in the process.

\subsection{Testing procedures}

To introduce the test procedure that will be used below to detect the order of integration, consider $\left\{y_{t}\right\}$ generated by an $I\left(d_{0}\right)$ process, as in (1) with $\mu=0$ and where $\left\{\varepsilon_{t}\right\}$ is a stationary process. The error process can encompass both stationary and invertible ARMA and ARFIMA models as particular cases.

The main interest of this paper lies in testing whether $d_{0}=d$, with $d \in \mathbb{R}$ being specified a priori, against the alternative for which the order of integration $d_{0}=d+\theta$, with $\theta \neq 0$. Thus, the hypothesis of interest can be stated as

$$
\mathrm{H}_{0}: d_{0}=d \quad \text { or } \quad \mathrm{H}_{0}: \theta=0
$$

against the alternative hypothesis $\mathrm{H}_{1}: d_{0} \neq d$, or $\mathrm{H}_{1}: \theta \neq 0$.

It is customary in the literature related to fractional integration to assume $\varepsilon_{t} \mathbb{I}_{(t \leq 0)}=$ 0, either explicitly (e.g., Tanaka 1999; Demetrescu et al. 2008) or indirectly (e.g., Nielsen 2004, 2005). This restriction ensures that the observable process is welldefined in the mean-square sense regardless of the values of $d$; see Marinucci and Robinson (1999) and Robinson (2005) for further details.

Thus, to test (2) we consider a procedure which is based on a linear regression framework and which is asymptotically equivalent to an LM test statistic. The regression-based approach was pioneered by Agiakloglou and Newbold (1994) for the context of fractional integration at the zero frequency and further developed in Breitung and Hassler (2002), Hassler and Breitung (2006), and Demetrescu et al. (2008) for the same context and generalized by Hassler et al. (2009) to other frequencies. Regression-based tests are particularly useful for the empirically relevant case in which data exhibit weak correlation. The testing strategy is based on the following auxiliary regression,

$$
\varepsilon_{d t}=\phi \varepsilon_{d, t-1}^{*}+\sum_{i=1}^{p} \zeta_{i} \varepsilon_{d, t-i}+e_{t p}, \quad t=p+1, \ldots, T
$$

where $\varepsilon_{d t}:=(1-L)_{t}^{d} \varepsilon, \varepsilon_{d, t-1}^{*}:=\sum_{j=1}^{t-1} \frac{1}{j} \varepsilon_{d, t-j}$ and $p$ represents the order of augmentation considered. Regarding the choice of $p$, Demetrescu et al. (2008) analyze the performance of several procedures to determine the order of augmentation, $p$, of the test regression in finite samples and conclude in favor of the rule of thumb 
proposed by Schwert (1989), which shows relatively good performance. This rule sets $p=\left[k(T / 100)^{1 / 4}\right]$, where $k$ is a positive constant (typically $k=4$ or $k=12$ ) and $[\cdot]$ denotes the integer value of the argument.

The statistical properties of the least squares estimates of $\phi$ under the null differ from those under the alternative hypothesis, which provides the basis to statistically identify the order of integration of the data. Furthermore, the problem of short-run dynamics can easily be handled in the regression context by means of augmentation as suggested in (3) and in line with the well-known Dickey-Fuller (DF) test. As discussed in Breitung and Hassler (2002), the auxiliary regression in (3) follows the same logic of the Dickey-Fuller regression and the Wald test in Dolado et al. (2002). Nevertheless, meaningful differences arise since in the DF test the regressor is non-stationary, I (1), under the null hypothesis, whereas $\varepsilon_{d, t-1}^{*}$ is (asymptotically) stationary, I (0), owing to the different types of weights used in constructing these variables.

A further interesting property of this procedure is that the parameter estimates of (3) converge to a normal distribution, i.e., $\sqrt{T}\left(\beta_{T}-\mu_{0}\right) \Rightarrow \mathcal{N}(\mathbf{0}, \Omega)$ where $\beta:=$ $\left(\phi, \zeta_{1}, \ldots, \zeta_{p}\right)^{\prime}, \beta_{T}$ is the $(p+1)$ vector of parameter estimates of the pth order augmented auxiliary regression in $(3), \mu_{0}:=\left(0, a_{1}, \ldots, a_{p}\right)^{\prime}$, with the $a_{i}$ parameters corresponding to the autoregressive coefficients in $\left(1-\sum_{i=1}^{p} a_{i} L\right) \varepsilon_{t}=v_{t}$, and $\Omega:=$ $\left(\Omega_{p}^{*}\right)^{-1} \Lambda_{p}\left(\Omega_{p}^{*}\right)^{-1}$ where $\Omega_{p}^{*}:=E\left(\mathbf{X}_{t p}^{*} \mathbf{X}_{t p}^{*}\right), \Lambda_{p}:=E\left(v_{t}^{2} \mathbf{X}_{t p}^{*} \mathbf{X}_{t p}^{*}\right)$ and $X_{t p}^{*}:=$ $\left(\varepsilon_{d, t-1}^{*}, \varepsilon_{d, t-1}, \ldots, \varepsilon_{d, t-p}\right)^{\prime}$; for details see Demetrescu et al. (2008) and Hassler et al. (2009).

Owing to asymptotic normality, we can easily test $\mathrm{H}_{0}: \theta=0$ by means of a test statistic based on a Wald test for $\mathrm{H}_{0}: \phi=0$ in the auxiliary regression. Note that, although the functional form of a Wald-type test is considered, the testing procedure is an LM test because it builds directly on the gradient of the likelihood function; see Hassler et al. (2009).

Hence, considering an $1 \times(1+p)$ vector $R$, such that $R=[1,0, \ldots, 0]$ the Wald-type test statistic on the estimates of the augmented auxiliary regression is given by,

$$
\Upsilon=\left[\sqrt{T} \mathbf{R} \beta_{T}\right]^{\prime}\left[\mathbf{R} \widehat{\mathbf{V}}_{\mathbf{T}} \mathbf{R}^{\prime}\right]^{-1}\left[\sqrt{T} \mathbf{R} \beta_{T}\right]
$$

with $\widehat{\mathbf{V}}_{\mathbf{T}}$ being the sample estimate of the covariance matrix of $\beta_{T}$ such that

$$
\widehat{\mathbf{V}}_{\mathbf{T}}=\left(\frac{1}{T} \sum_{t=p+1}^{T} \mathbf{X}_{t p}^{*} \mathbf{X}_{t p}^{* \prime}\right)^{-1}\left(\frac{1}{T} \sum_{t=p+1}^{T} \widehat{e}_{t p}^{2} \mathbf{X}_{t p}^{*} \mathbf{X}_{t p}^{* \prime}\right)\left(\frac{1}{T} \sum_{t=p+1}^{T} \mathbf{X}_{t p}^{*} \mathbf{X}_{t p}^{* \prime}\right)^{-1},
$$

where $\widehat{e}_{t p}$ denotes the estimated residuals from (3). Under some regularity conditions, it follows from Demetrescu et al. (2008) and Hassler et al. (2009) that $\Upsilon \Rightarrow \chi_{(1)}^{2}$. Note that $\Upsilon$ can simply be obtained from (3) as the squared $t$-statistic to test $\phi=0$. Furthermore, using a consistent estimate of the asymptotic covariance matrix in (4) based on a version of the Eicker-White estimator, the test presented above can be made robust against conditional heteroskedasticity of unknown form (see Kew and Harris 2008). 
Hassler et al. (2009) also suggest that the test procedure in (4) provides a valuable tool to construct confidence sets that include the true value, $d \in \mathbb{R}$, with $(1-\alpha) \%$ asymptotic nominal probability. These confidence sets can be obtained from a grid search on $\Theta$, a compact subset of $\mathbb{R}$. For instance, denote $\widehat{\Upsilon}_{d}$ as the value of the test statistic in (4) when evaluated at any $d \in \Theta$, and let $\mathcal{D}_{T \alpha}=$ $\left\{d: \operatorname{Pr}\left[\widehat{\Upsilon}_{d} \leq \chi_{(1)}^{2}\right] \leq 1-\alpha\right\}$, i.e., the subset of $\Theta$ containing the values for which the null hypothesis cannot be rejected at the $(1-\alpha) \%$ nominal confidence level. If $\mathcal{D}_{T \alpha}$ is in the interior of $\Theta$, then the probability of $d$ being in the closure of $\mathcal{D}_{T \alpha}$ is at least $(1-\alpha) \%$.

A further important point to note is that so far in our analysis, we have focused on the model $(1-L)^{d}\left(y_{t}-\mu_{t}\right)=\varepsilon_{t}$, by allowing for different dynamics in $\varepsilon_{t}$, and restricting $\mu_{t}=0$ for simplicity of analysis. However, as discussed in Breitung and Hassler (2002), one can simply deal with non-zero deterministic patterns, $\mu_{t} \neq 0$, by detrending $\left\{y_{t}\right\}$ prior to computing the relevant tests, which does not affect the limit distribution of the relevant statistics (see also Robinson 1994).

\subsection{Testing against breaks in $d$}

The analysis of breaks in the order of fractional integration has received considerable attention in recent literature; see, among others, Gil-Alana (2008), Sibbertsen and Kruse (2009), Hassler and Scheithauer (2011), Yamaguchi (2011), Martins and Rodrigues (2014) and Hassler and Meller (2014). In this paper, we consider splitting the sample exogenously into $b$ non-overlapping subsamples or blocks,

$$
t \in\left[T_{i-1}+1, T_{i}\right], \quad T_{i}=\left\lfloor\tau_{i} T\right\rfloor, i=0,1, \ldots, b,
$$

where $\tau_{0}=0$ and $\tau_{b}=1$, such that each block contains $T_{i}-T_{i-1}$ observations.

Shimotsu (2006) considered the specific situation where all blocks are of equal sample size $T / b$ and constructed a Wald-type statistic for testing the joint overall null hypothesis $d_{1}=\cdots=d_{b}$, where $d_{i}$ denotes the order of fractional integration over $\left[T_{i-1}+1, T_{i}\right]$. In this paper, we will follow Hassler and Meller (2014) in order to have a higher degree of flexibility. First, if the true breaks are not equi-spaced, then a correct timing is desirable to increase power. Second, we wish to compare the blocks separately and test, for example, whether the order of integration in the first and last sub-periods are equal. Hence, we consider the null hypotheses:

$$
\mathrm{H}_{0}^{(i, j)}: d_{i}=d_{j}, \quad i \neq j
$$

For given break fractions, $\tau_{i}, i=1, \ldots, b$, one may compute local Whittle [LW] estimators or exact LW [ELW] estimators; see Robinson (1995) and Shimotsu and Phillips (2005), respectively, for definitions and asymptotic properties. Since ELW is also valid in the region of non-stationarity, we will employ this estimator in our application. Thus, the subsample estimators $\widehat{d}_{i}, i=1, \ldots, b$, are semi-parametric and require the choice of a bandwidth $m_{i}$ for each block, such that, 


$$
\frac{1}{m_{i}}+\frac{m_{i}}{T_{i}-T_{i-1}} \rightarrow 0
$$

as the sample size (in each block) increases. To test $\mathrm{H}_{0}^{(i, j)}$, Hassler and Meller (2014) suggest the computation of the appropriately normalized difference of two subsample estimators. Hence, based on the ELW estimators, $\widehat{d}_{i}$ and $\widehat{d}_{j}, i \neq j$, of the order of fractional integration $d_{0}$ computed from two non-overlapping subsamples where the bandwidths $m_{i}$ and $m_{j}$ satisfy ( 7), $i, j=1, \ldots, b$, the test statistic proposed by Hassler and Meller (2014) is,

$$
\mathcal{S}_{i j}=2 \frac{\sqrt{m_{i} m_{j}}}{\sqrt{m_{i}+m_{j}}}\left(\widehat{d}_{i}-\widehat{d}_{j}\right) .
$$

Under $\mathrm{H}_{0}^{(i, j)}$, (7) and the assumptions in Shimotsu (2006, Lemmas 1 and 3), it thus follows that

$$
\mathcal{S}_{i j} \stackrel{D}{\rightarrow} \mathcal{N}(0,1),
$$

where $\stackrel{D}{\rightarrow}$ denotes convergence in distribution.

\section{Empirical analysis}

\subsection{The world tourism cycle}

Tourism is often described as a "fragile" industry in that demand is highly vulnerable to shocks, such as, e.g., wars, outbreaks of diseases, terrorism attacks, economic fluctuations, currency and political instability, and energy prices (see Neumayer 2004). Over the period under analysis (1996-2014), several such negative events have occurred of which some affected one or more specific regions, and others had a more global impact, consequently impacting differently on the world tourism exports cycle. Figure 1 depicts the evolution of the world tourism cycle between 1985 and 2014 .

The cycle presented in Fig. 1 is extracted from the world tourism exports series provided by UWTO using a state space approach; see Gouveia et al. (2013) for details. In this Figure we identify three major periods: (1) a severe decline between 1996 and 2002; (2) a marked recovery from 2002 to 2007 and, (3) a strong decline since the recent financial crises (from 2007 to today). It is important to note that, since the tourism sector is highly sensitive to external events, in a global market, different events may have heterogeneous impacts across regions and countries. The sharp decline in the mid 1990s and the fluctuations that followed are not independent from the events that marked the last decades. Specifically, the second half of the 1990s will be remembered for the severe crises that shook East Asia in 1997, and Brazil and the Russian Federation in 1999. The Asian financial crisis led to the devaluation of currencies against the dollar in Thailand, Malaysia, Indonesia, Philippines and South Korea, and to the substantial fall in asset prices in their markets (see, inter alia, Cohen and Neal 2010). However, with time this regional crisis became what was called "the first great crisis of the 


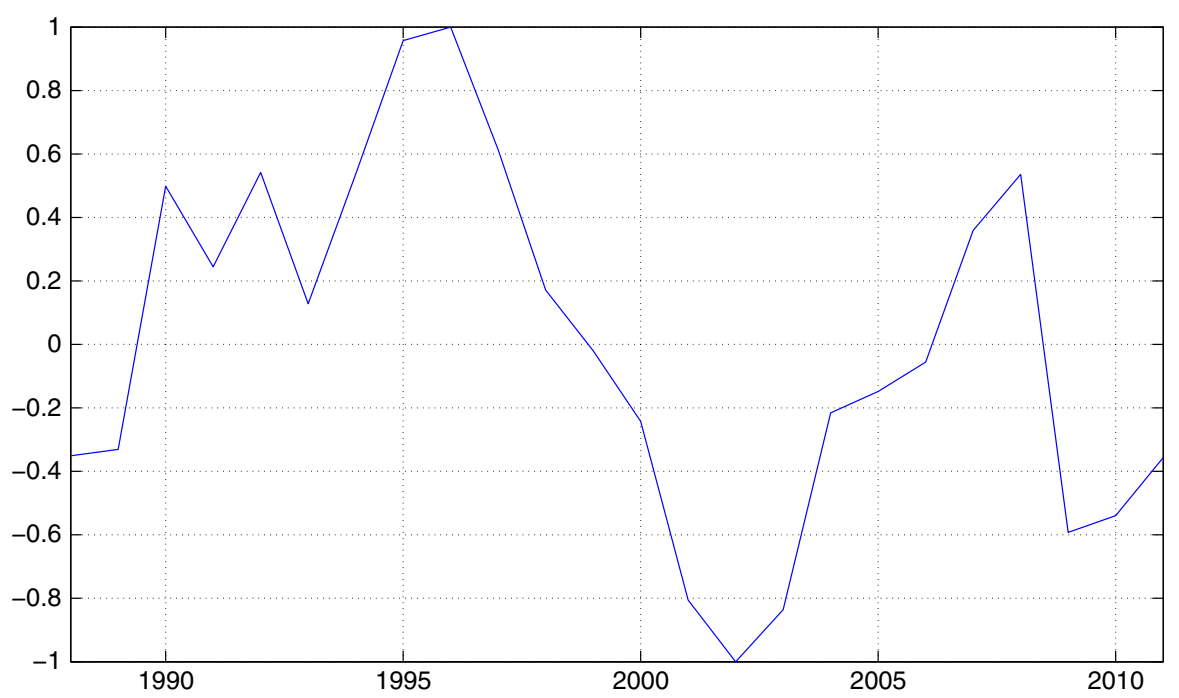

Fig. 1 The world tourism cycle between 1985 and 2014

globalized markets", severely impacting the Far East countries; see Gouveia et al. (2013).

The period between 2000 and 2005 is marked by a number of major events that had significant negative impacts on international travel and tourism; among these events are the terrorist attacks of September 11, 2001. It is well documented in the literature that the impact of terrorism on a country's economy can be large, leading to unemployment, deflation, crime and other economic and social consequences (see, Blomberg and Hess 2002; Blomberg et al. 2004a, b; Abadie and Gardeazabal 2007). The contribution of tourism and travel to both industrialized and developing countries is now so great that any downturn in the level of activity in the industry is a cause of concern. The repercussions extend beyond activities directly associated with tourism, notably airlines, hotels and catering, to sectors that supply intermediate or final goods that are purchased by firms and employees in the industry, so that all sectors of the economy are affected to a greater or lesser extent. Additionally the invasion of Afghanistan (October, 2001), the Bali bombings (October, 2002), the Severe Acute Respiratory Syndrome (SARS) outbreak (November, 2002), the war in Iraq (Spring, 2003), the Madrid train bombings (March 2004), the Indian Ocean tsunami (December, 2004) and the London bombings (July, 2005) all contributed to a decline of tourism demand. These events had different impacts on the countries directly affected as well as on neighboring countries and regions (see e.g., Edmonds and Mak 2005). As a consequence of the variety of negative events and of these occurring in different regions, an interesting result that we can observe from Fig. 1 is that the joint impact on the world's tourism demand cycle seems to have been more severe than that of the current financial crisis. In addition to the Gulf war and terrorism attacks, the SARS outbreak that started in China in November 2002, and spread fast over the world (in August 2003 it had spread to 29 countries and three regions) and which aggravated the situation. The 
most affected areas were China, Hong Kong, Taiwan and Singapore, countries with a significant weight in terms of regional tourism exports. The impact was so strong that the World Bank predicted that output growth in East Asia would fall by almost 1\% point in 2003. Finally, the recent economic and financial downturns have seriously affected economies around the world including, the tourism industry from 2007 to present (Smeral 2009, 2010; Barda and Sardianou 2010). Many destinations in the world reported negative growth and global tourism was severely affected in the process, causing major changes in this sector (Hall 2010; Pizam 2009; Papatheodorou et al. 2010; Song and Lin 2010). During 2008 the world economy faced a very volatile and unstable situation. Although the tourism sector seemed to resist the crisis, contrary to other sectors, such as construction, real estate or the car industry, its performance was also conditioned by other factors. According to INE (2008), several events impacted negatively on tourism, such as, (1) the military conflicts in Iraq, Afghanistan, Pakistan, Palestine, Sri Lanka and India, and the Mumbai terrorist attacks in November 2008; (2) the frequent climatic problems around the globe, such as, the floods in China, Myanmar, Brazil, Mexico and the UK; the heat waves and fires in Greece and Italy, the cyclones and tornadoes, especially in the Caribbean and surrounding countries, earthquakes in China, and the volcanic eruptions, particularly in Chile; and (3) the high oil prices registered for over six months of the year and the consequent difficulties felt by airline companies.

The year of 2008 was also characterized by large volatility in the level of exchange rates of the main world currencies. According to data from the Eurostat and IMF (2010, 2011), the dollar and the euro registered significant gains against the currencies of several emerging markets. On the one hand, these valuations made these markets more attractive in terms of tourist destinations and, on the other, Europe and the US lost competitiveness as destinations. The significant gains in the dollar and the euro resulted in the gradual reduction in the propensity of British tourists (one of the leading source markets), to travel to Europe in particular. Furthermore, from the second half of 2008 onward, the growing unemployment rates, with direct consequences on consumers and companies' confidence levels, as well as on domestic demand, started the downward cycle in Europe, US and Japan, reflecting itself in the contraction of global tourism and resulting, especially for Europeans, in the choice of closer destinations. The tourism sector which had shown sustained growth worldwide in previous years, registered a contraction in activity in 2009 which, according to the World Tourism Organization and International Labour Organization (2013), resulted in generalized breaks in tourism revenues. Further, the continued increase in unemployment and reduced access to credit and frozen wages determined the reduction in the propensity of tourists of major outbound markets to travel, particularly Europeans. The economic recovery of the outbound markets, as well as reduced levels of unemployment are taken, as the main constraints of the tourism sector's recovery. During 2009 considerable exchange rate fluctuations continued to exist. Many emerging countries in terms of tourism, which in 2008 had depreciated their currencies against the dollar and the euro, observed an appreciation of their currencies, although unable to reach previous levels (IMF 2010), but sufficiently enough to allow Europe and the US to regain competitiveness as tourism destinations. 
In 2010, and according to the World Tourism Organization (UNWTO 2013), the tourism sector observed a significant recovery of the fall registered in 2009. This recovery is also mentioned in Instituto Nacional de Estatística (2009), who refer to an inversion of the downward trend of the world economy observed since 2008. All major economies recorded positive real GDP growth, when in the previous year only in emerging and developing economies this had occurred (International Monetary Fund 2012). Nevertheless, the effects of the global economic crisis were still visible to the extent that the recovery of tourist revenue was more modest than that observed in the number of tourists. The amplitude of variations in the recovery of tourist revenue in 2010 differs across economies. The growth observed in China was very significant in 2010, a country that increased its position in all ranks of the main indicators of the sector, assuming an important position in terms of tourism, both as receiver and as an emitter. The EU27 recorded the lowest worldwide slowdown between 2010 and 2011. In emerging and developing economies, growth was lower than in the previous year but progressed at a rate that was more than triple of that observed in the EU or US (INE 2011).

At present, uncertainty about the duration, depth, and implications of the global economic crisis still persist and is transmitted into the tourism industry. Unemployment is still increasing in key tourism origin markets, exchange rates and oil prices are still fluctuating, and restrictions on bank credit facilities remain. However, the future prospects for the sector are promising. The World Trade Organization announced that international tourism increased by about $4 \%$ in 2012 compared to 2011. In 2012, for the first time, a billion travelers crossed the borders, and for 2013 this organization predicted growth between 3 and 4\% in international tourism (UNWTO 2013).

\subsection{Sample descriptive statistics}

Our dataset is composed by the travel and leisure sector equity indices spanning the period from December 29, 1995, to August 22, 2014. All data were obtained from Datastream. Given the typical leading indicator behavior of financial variables, understanding and characterizing the properties of these indices may contribute to clarify the behavior of the tourism sector and its resilience to crises. We provide results for the whole sample period (in a total of 4866 observations) and for three sub-periods defined by the world tourism cycle regimes depicted in Fig. 1: sub-period 1 corresponding to the period from December 29, 1995, to December 31, 2002 (1828 observations); sub-period 2 from January 01, 2003, to August 31, 2007 (1218 observations); and sub-period 3 from September 3, 2007, to August 22, 2014 (1820 observations). Subperiod 1 corresponds to a period in which there is a considerable decline in the cycle; Sub-period 2 corresponds to an expansion period; and finally, Sub-period 3 includes the recent financial crisis and the Euro area sovereign debt crisis, which started in early 2010 and has led to increased pressure in financial markets (particularly in Europe). This time disaggregation is crossed with a disaggregation at the regional level. We provide evidence at the aggregate level, as well as at the disaggregate level for several regions and subregions. In what follows, we consider: Europe (distinguishing European but non-European Union member states, European Union member 
states and European Monetary Union-EMU, henceforth-member states), America (distinguishing Latin American countries and North American countries), and Asia (distinguishing Far East countries and Southeastern Asian countries).

To understand the dynamics of the world tourism cycle and of the travel and leisure indices over the period under analysis, in what follows we provide a descriptive analysis that illustrate the persistence properties of the log of absolute value of tourism and leisure equity index returns and of its components, in particular, hotels, airlines and travel and tourism, and relate them to the tourism exports cycle. The variable used in the analysis is constructed from the observable series of equity index returns $r_{t}$, i.e., $z_{t}=$ $\log \left(\left|\widehat{r}_{t}^{*}\right|\right), t=1, \ldots, T$, where $\widehat{r}_{t}^{*}=r_{t}-\widehat{\alpha}_{0}-\widehat{\alpha}_{1} r_{t-1}-\cdots-\widehat{\alpha}_{p} r_{t-p}$, with $p$ selected based on the Schwarz information criteria (SIC, hereforth). The results are reported in Tables 1, 2, 3 and 4.

We observe that at the aggregate world level, the travel and leisure index average returns follows the tourism cycle regimes, recording a negative value in the first subperiod, a significant increase in the period 2003-2007 and a sharp decline afterward. The volatility enacts a decreasing behavior in 2003-2007 and an inversion in the following sub-period. The distribution seems to be left skewed (negative asymmetric) and leptokurtic. This pattern seems to be shared by all regions and subregions. By observing the behavior of the index components, we conclude that the major contributions for the negative values of the travel and leisure index average returns in subsamples 1 and 3 come from the airlines index returns. Volatility also follows a similar pattern across regions and sub-periods. The volatility of the travel and leisure index is higher than in subsample 2 for all regions and subregions and in all components of the global index. Overall, data confirms that periods of crisis bring tourism reductions and consequently reduced returns and higher volatilities.

\subsection{Order of fractional integration}

To investigate the series' persistence upon the occurrence of economic disruptions, we analyze in this section whether the order of integration of the series has changed over the period under analysis. In what follows, we first estimate the order of fractional integration, $d$, computed using the ELW estimator $\left(\widehat{d}_{\mathrm{ELW}}\right)$, as well as their $95 \%$ confidence intervals (which we denote by $\mathrm{CI}_{\mathrm{ELW}}^{95 \%}$ ) for the reference regions under analysis. The bandwidth used in the ELW estimator is $m=T^{0.65}$ for the full sample and similarly $m_{i}=\left(T_{i}-T_{i-1}\right)^{0.65}$ for the subsamples. We also compute LM tests based confidence intervals, which we denote by $\mathrm{CI}_{\mathrm{LM}}^{95 \%}$. These confidence intervals are computed via a grid search, based on which we determine the range of values of $d$ not rejected by the fractional integration test at the 5\% significance level. Following Hassler et al. (2009, Remark 2.7) we numerically obtain $95 \%$ confidence intervals. The results are reported in Tables 5, 6, 7 and 8 for the whole sample period and for each subsample.

From Tables 5, 6, 7 and 8 we observe that the estimates of the fractional integration order ranges between 0.26 and $0.35\left(0.26 \leq \widehat{d}_{\mathrm{ELW}}^{\mathrm{All}} \leq 0.35\right)$ for travel and leisure index returns, from 0.22 to $0.35\left(0.22 \leq \widehat{d}_{\mathrm{ELW}}^{\mathrm{All}} \leq 0.35\right)$ for the $\log$ of absolute hotel equity index returns, from 0.24 to $0.33\left(0.24 \leq \widehat{d}_{\mathrm{ELW}}^{\text {All }} \leq 0.33\right)$; for the absolute airlines equity index returns and from 0.22 to 0.38 (that is $0.22 \leq \widehat{d}_{\mathrm{ELW}}^{\mathrm{All}} \leq 0.38$ ) for the $\log$ 


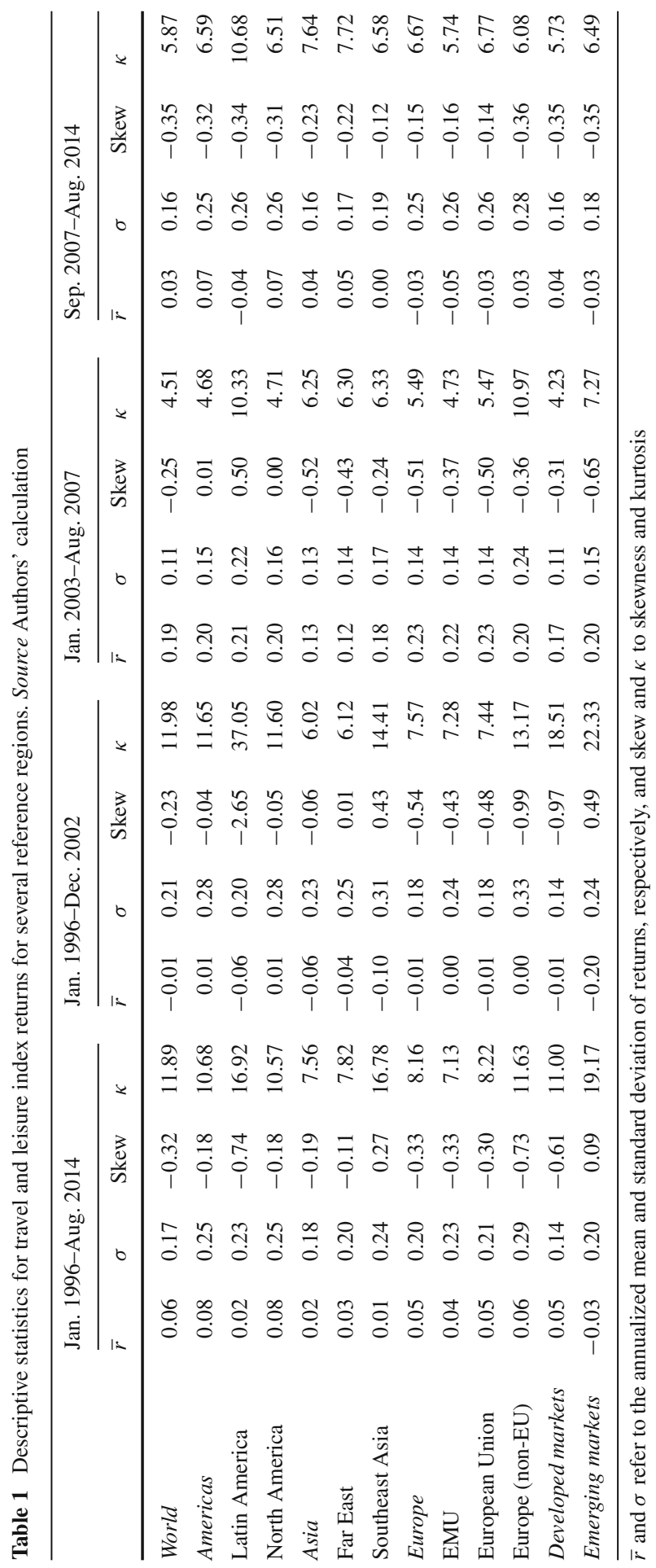




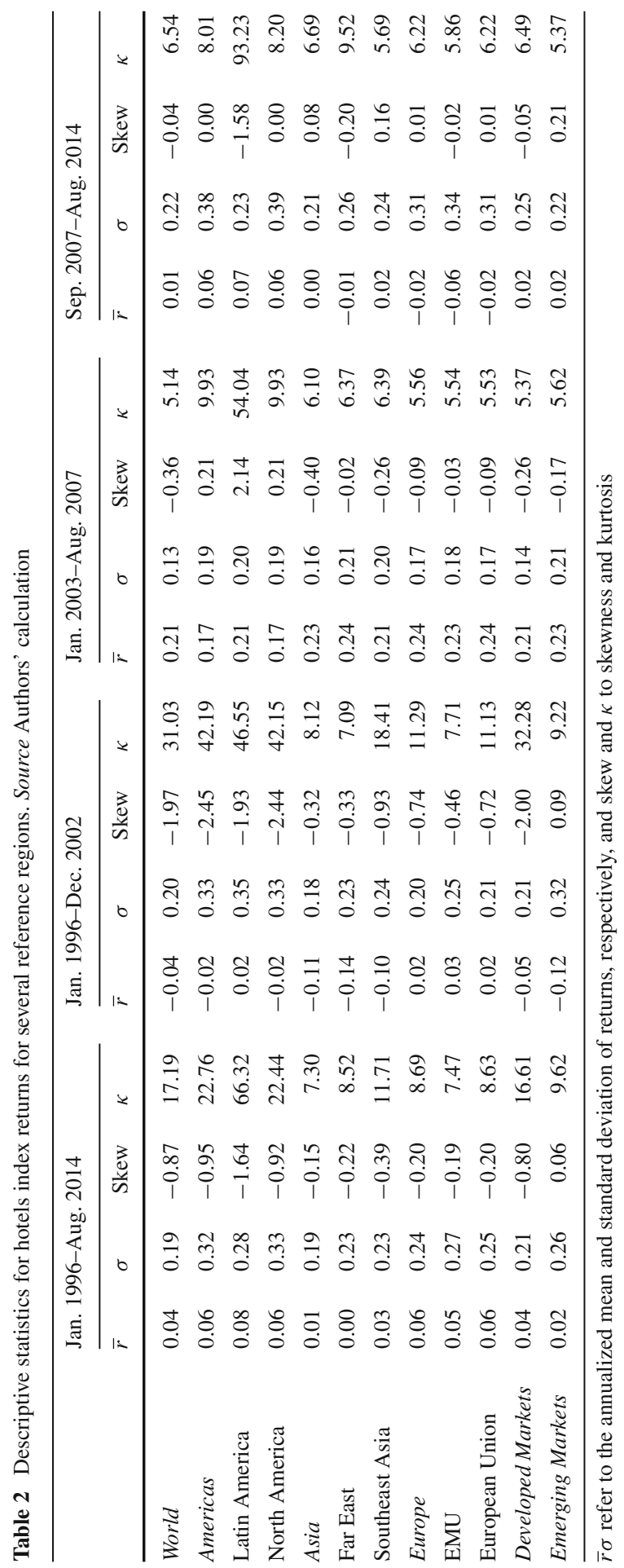




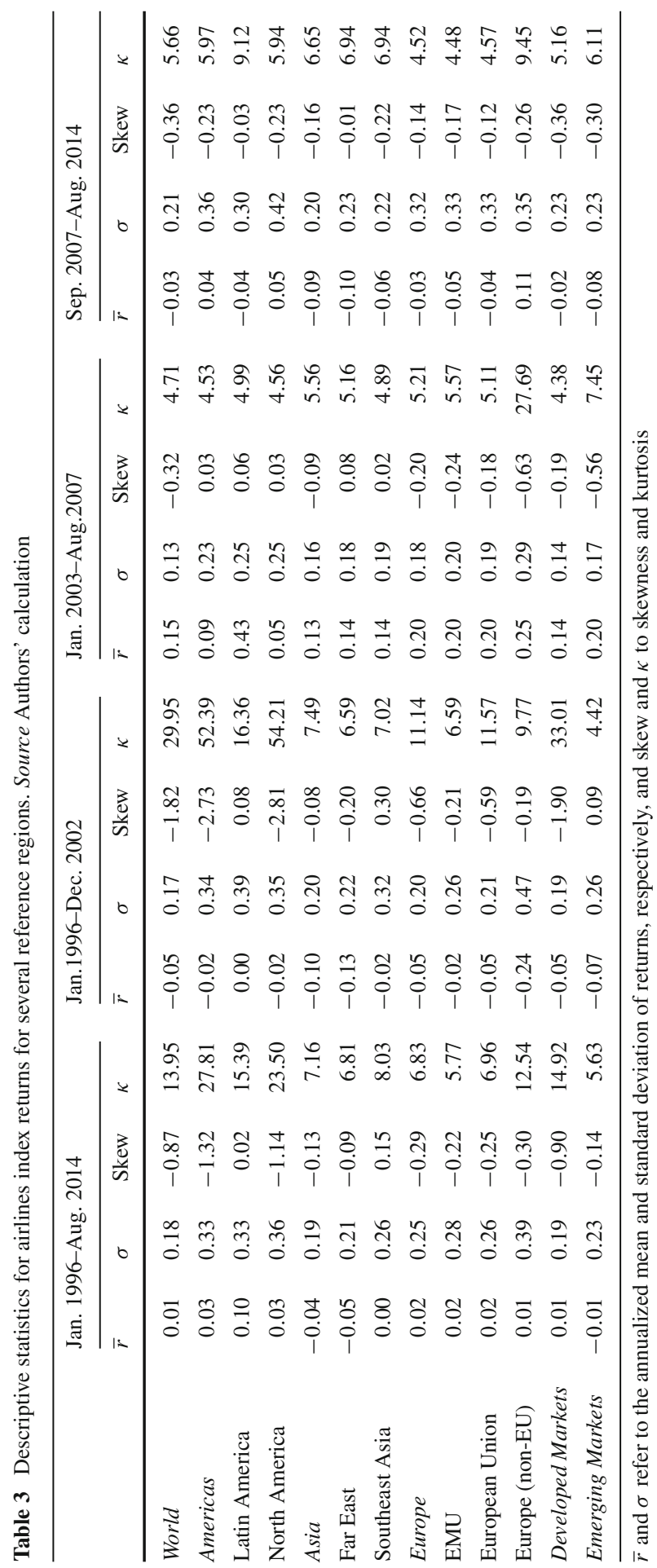




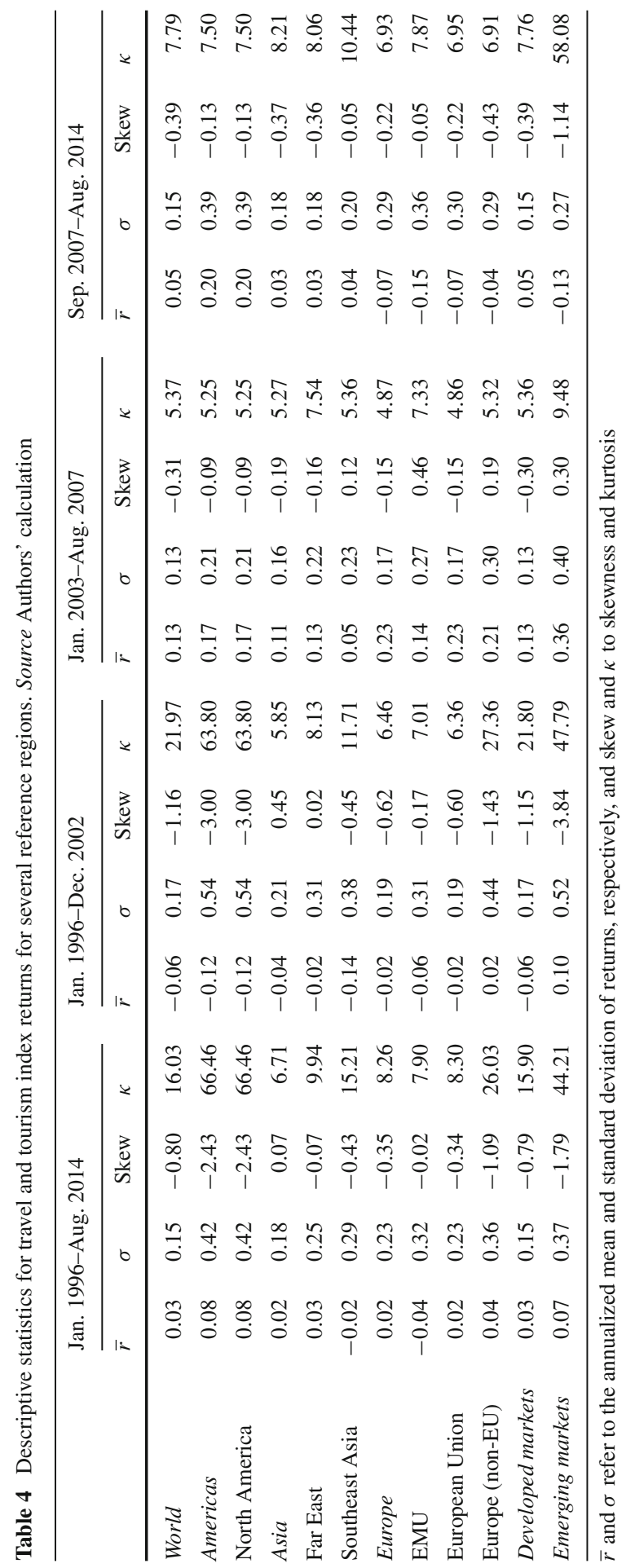


of absolute travel and tourism equity index returns. We observe that the estimates of $d_{i}$ in subsample 1 fall between 0.23 and 0.32 for travel and leisure, between 0.11 and 0.29 for hotels, between 0.15 and 0.29 for airlines, and between 0.16 and 0.27 for travel and tourism. In subsample 2, we observe that those ranges for each index are $0.05-0.26,0.09-0.25,0.12-0.32$ and $0.10-0.26$, respectively. Finally, for subsample 3 we observe that the estimates of $d_{i}$ range from 0.16 to 0.31 for travel and leisure, from 0.17 to 0.33 for Hotels, from 0.22 to 0.30 for airlines and from 0.19 to 0.33 for travel and tourism. These results seem to suggest that although in general the log of absolute equity index returns are stationary, there is heterogeneity across indices and across subsamples which is corroborated by the computed confidence intervals (Tables 5, 6, 7, 8). From the analysis of the confidence intervals we observe that, although both provide qualitatively the same conclusions with regard to the dynamics of the persistence over the three subsamples considered, there are shifts of both intervals from subsample 1 to subsample 2, suggesting persistence decrease, and shifts from subsample 2 to subsample 3, suggesting persistence increase. Therefore, there is evidence of higher persistence during periods of tourism activity contraction and lower persistence during periods of activity expansion.

The regional disaggregation also highlights the existence of heterogeneity across regions and enables us to identify the regions where the series' persistence is higher. Considering the travel and leisure index and the full sample, the region with the lowest order of integration of the log of absolute equity index returns is Asia $\left(\widehat{d}_{\mathrm{ELW}}^{\mathrm{All}}=0.26\right)$ and the region reporting the highest persistence is North America $\left(\widehat{d}_{\mathrm{ELW}}^{\mathrm{AIl}}=0.35\right)$. However, if subsample 1 is considered, the lowest persistence is observed in European countries not belonging to EU $\left(\widehat{d}_{\mathrm{ELW}}^{\mathrm{Sub} 1} \leq 0.23\right)$, while the highest is observed for Southeast Asia $\left(\widehat{d}_{\mathrm{ELW}}^{\mathrm{Sub} 1} \leq 0.32\right)$. Persistence decreases in all regions in subsample 2, from 2003 to 2007, when the lowest value was observed for European countries $\left(\widehat{d}_{\mathrm{ELW}}^{\text {Sub1 }} \leq 0.05\right)$ and the highest for Latin American countries $\left(\widehat{d}_{\mathrm{ELW}}^{\text {Sub1 }} \leq 0.26\right)$. The following period reports persistence increase in all regions with the exceptions of Far East countries and Latin American countries.

The disaggregate analysis by components, when crossed with the regional and time disaggregation, uncovers different patterns. In general, the persistence reduction in subsample 2 and the persistence increase in subsample 3 are observed in almost all regions. However, for the American countries and Emerging Markets, there is a steady increase of persistence over time in all components. This behavior also stands for hotels indices in the Southeast Asian countries and for airlines indices in the European Monetary Union countries.

An attempt to establish an association of these results with economic disruptions is direct. We notice that over the 1996-2002 period, the persistence levels are higher in regions directly or indirectly affected by economic instability, bomb attacks or natural disasters. Among these regions are the Southeast Asian countries, the European Monetary Union member States and the Latin American countries. Given the global impact of the 2007 financial crisis that enacted in the US but rapidly extended to other countries, and the sovereign debt crisis in Europe that followed, the highest persistence levels were observed again in the American countries, most of European countries and Southeast Asian countries. 


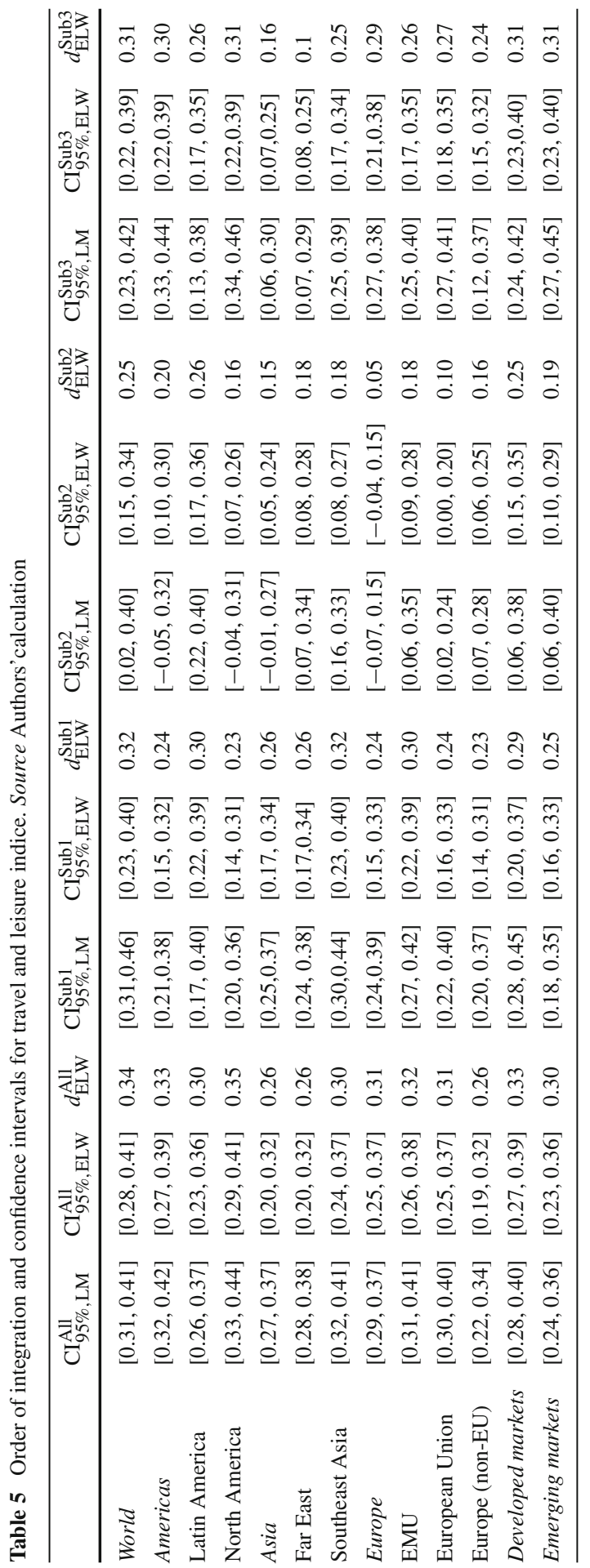




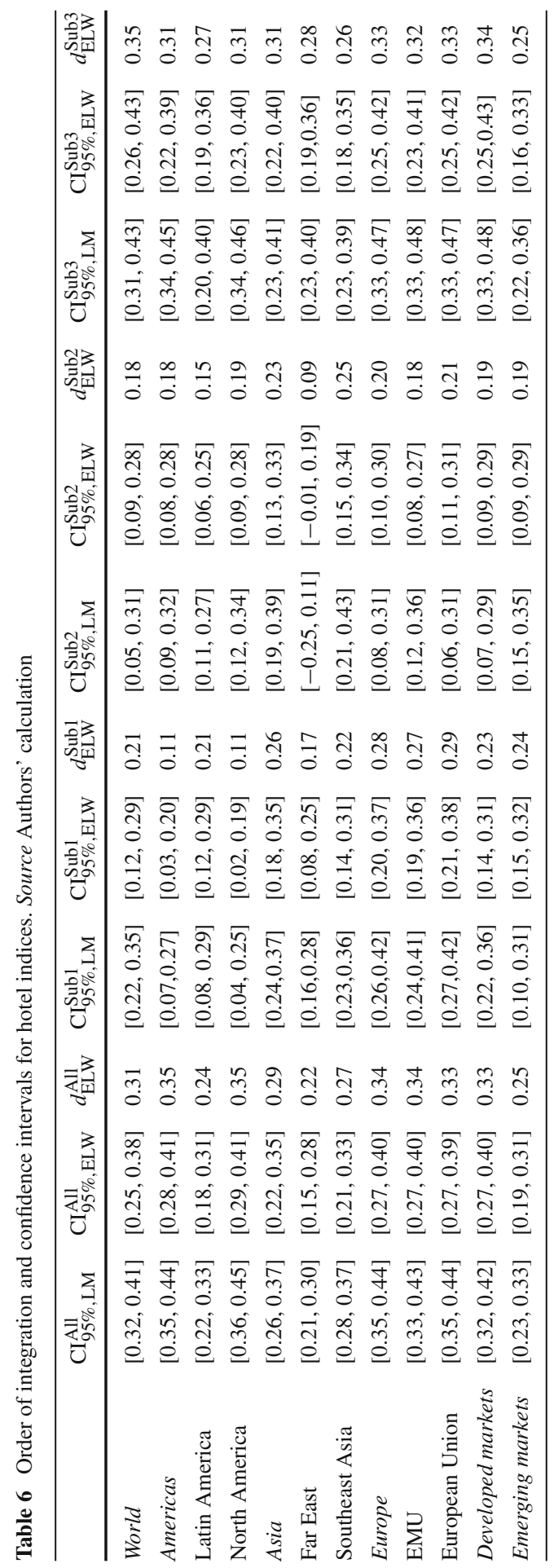




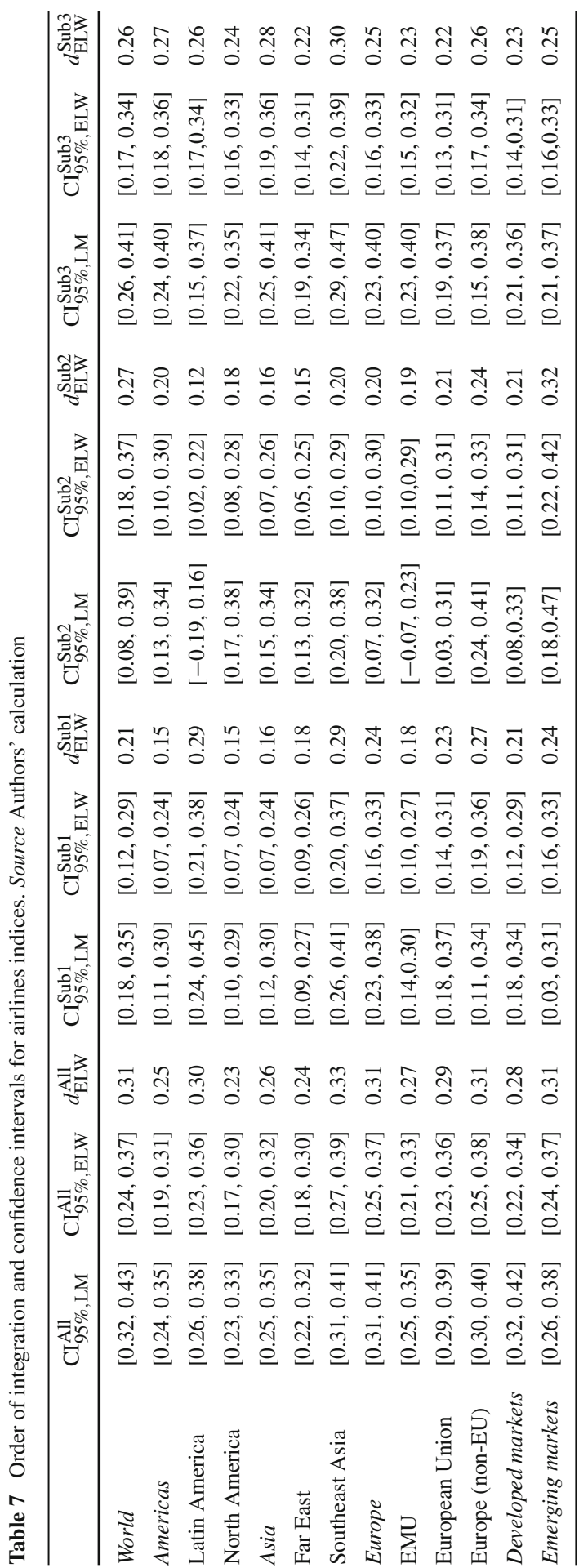




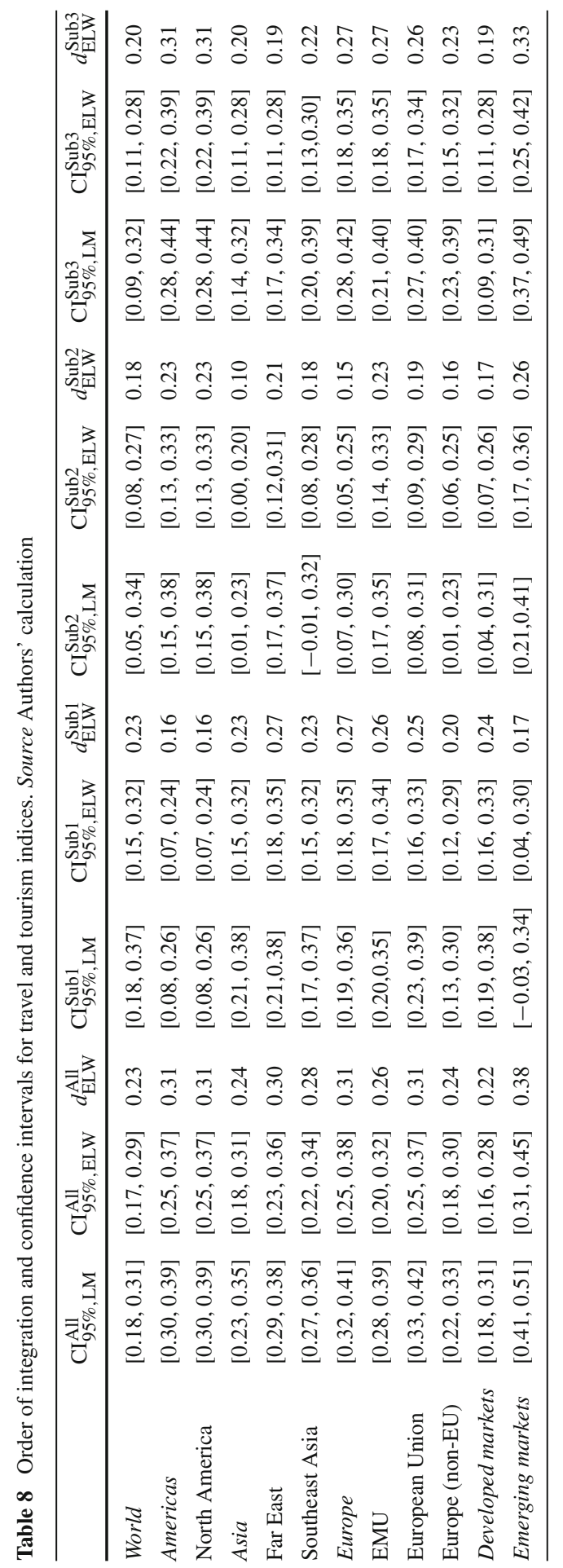




\subsection{Testing for breaks in persistence}

In this section, we formally investigate whether persistence has changed between the three periods under analysis and check the significance of changes detected in the previous subsection. Hence, based on the three subsamples considered, we expect that the order of integration decreases from subsample 1 to subsample 2 (i.e., $d_{1}>d_{2}$ ) and that it increases from subsample 2 to subsample 3 (i.e., $d_{3}>d_{2}$ ) and we therefore exploit this information using one-sided tests for breaks. However, we do not have any a priori expectations as to the direction of change from subsample 1 to subsample 3 , and therefore we apply two-sided tests in this case. Table 9 reports the test results.

From our conjecture, we expect $\mathcal{S}_{12} \geq 0$ if in fact a decrease in $d$ from subsample 1 to subsample 2 is observed and $\mathcal{S}_{23} \leq 0$ if an increase in $d$ occurs from subsample 2 to subsample 3 . The results in Table 9 are generally supportive of this conjecture. We notice that there are significant reductions of persistence of the travel and leisure index from subsample 1 to subsample 2 in almost all regions, with the exception of the American countries. Looking at hotels, airlines and travel and tourism indexes, we notice that these components exhibit different persistence regional patterns and therefore contribute differently to the overall result. In fact, significant persistence reductions were observed in the travel and tourism for Asia, and Europe, in Airlines for the South East Asian countries and Latin American countries and in Hotels for the European countries. In all other cases the test statistic assumes positive non-significant values. The results also confirm the occurrence of significant increases in persistence from subsample 2 to subsample 3 in almost all regions. The main source of this general persistence increase were Hotels for the American countries and European countries; Airlines for Southeast Asian countries; and travel and tourism for European countries. Other significant increases of persistence from subsample 2 to subsample 3 were observed in Hotels for Asia, Monetary Union member States, Far East countries and Latin American countries; Airlines for Asian and Latin American countries; and travel and tourism for Asian countries. Therefore, the results confirm the occurrence of a decrease of persistence from subsample 1 to subsample 2 and an increase from subsample 2 to subsample 3 for most regions. However, they do not confirm the existence of differences in persistence from subsample 1 to subsample 3 for the majority of the regions notwithstanding the different nature of the crisis that characterized these two periods. Considering the countries by their development levels, we notice that the groups of developed countries and emerging countries report significant persistence increases in hotels and travel and tourism indices, respectively, after 2007.

\section{Conclusion}

This paper uses fractionally integration approaches to test for the persistence of travel and leisure sector equity indices. Specifically, it attempts to check whether the series' memory is constant over time or subject to change. To test this null hypothesis, the sample period, that spans from 1996 to 2014, has been split into three non-overlapping subsamples where the break dates are given exogenously according to the World Tourism Cycle behavior. The first regime spans from January 1996 to December 


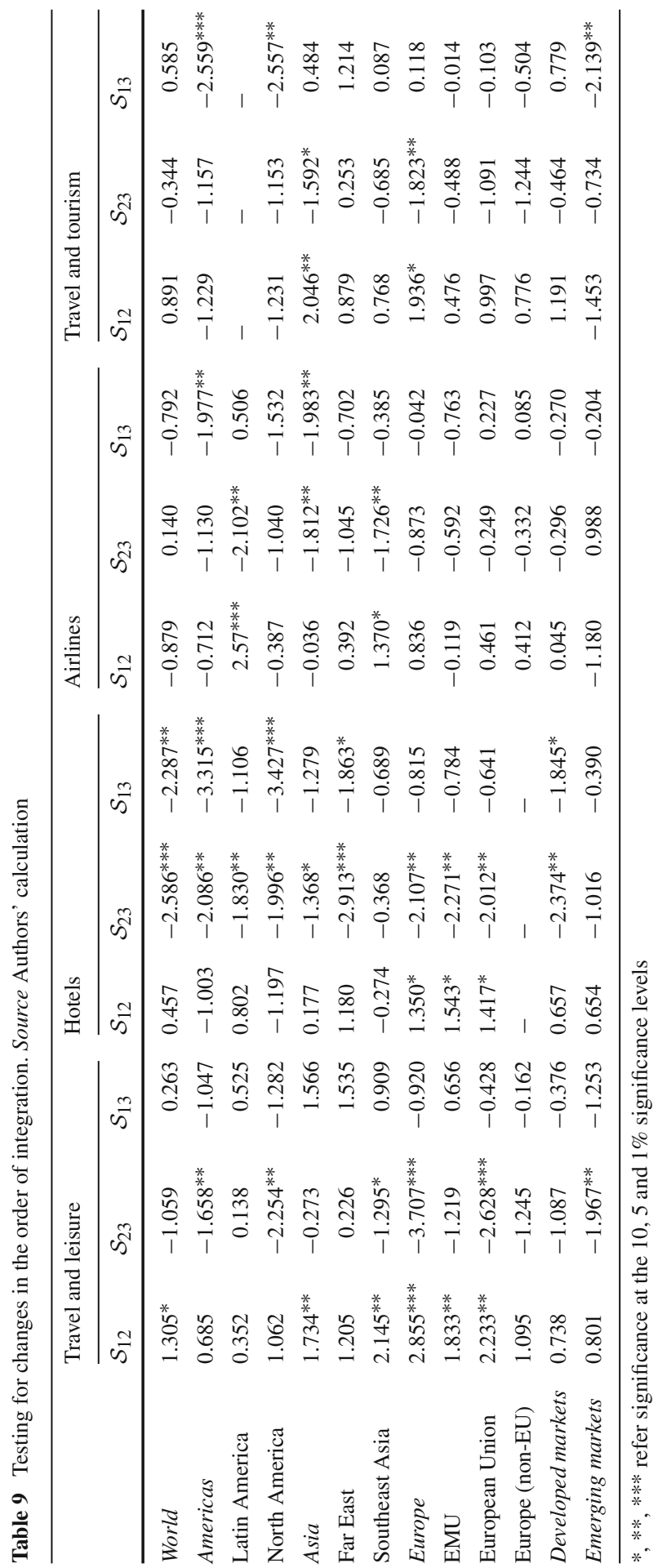


2002 which was characterized by a decreasing trend in tourism flows. The second regime ranges from January 2003 to August 2007 corresponding to a recovery period. Finally, the third regime runs from September 2007 to July 2014 and was characterized mainly by a deceleration of tourism activity. The analysis is conducted on a regional level, considering different reference regions and considering components of the travel and leisure equity indices. In particular, we consider hotels, airlines and travel and tourism indices returns to identify the relative importance on the aggregate result. The series' order of integration is estimated using the exact local Whittle estimator, for each sub-period, region and indices' component, as well as the corresponding confidence intervals. Then, the analysis is further developed by testing against the alternative that the respective memory differ for any two sub-periods. The test statistic is the normalized difference of the estimators and follows a limiting standard normal distribution under the null hypothesis of no change. We believe that results are very informative for both analysts, forecasters, investors and tourism agents in general.

The results highlight some important aspects. First, they reveal a decrease of persistence from the period 1996-2002 to the period 2003-2007 and an increase in the following period after 2007. Moreover, there is evidence that the level of persistence after 2007 is similar to that observed before 2002, which suggests that higher persistence levels are associated with periods marked by negative events which generate market adversities and consequently lead economic agents to become more riskadverse. In short, in the period that started with the recent financial crisis, the series' persistence reached the levels observed in the second half of the 1990s when several major negative events hit the economies worldwide. Second, the results provide some evidence that the regions more closely hit by negative economic events exhibit higher persistence levels. Specifically, the American countries, the Southeast Asian countries and most of the European countries were particularly affected by the Asian crisis in the 1900s and the recent financial crisis after 2007 and report higher persistence in those periods. Third, the persistence increase in these regions has been favored by a steady persistence increase of hotels and airlines indices in the Southeast Asian countries and European Monetary Union countries, respectively.

Acknowledgements We are grateful to Robert Kunst and an anonymous referee for useful comments and suggestions.

\section{References}

Abadie A, Gardeazabal J (2007) Terrorism and the world economy. Eur Econ Rev 57:1-27

Agiakloglou C, Newbold P (1994) Lagrange multiplier tests for fractional difference. J Time Ser Anal 15(3):253-262

Andersen TG, Bollerslev T, Diebold FX, Labys P (2003) Modeling and forecasting realized volatility. Econometrica 71:579-625

Andraz JM, Gouveia PM, Rodrigues PMM (2009) Modelling and forecasting the UK tourism growth cycle in Algarve. Tour Econ 15(2):323-338

Barda C, Sardianou E (2010) Analysing consumers' "activism" in response to rising prices. Int J Consum Stud 34:133-139

Blomberg SB, Hess GD (2002) The temporal links between conflict and economic activity. J Conflict Resolut 46(1):74-90 
Blomberg SB, Hess GD, Weerapana A (2004a) Economic conditions and terrorism. Eur J Political Econ 20(2):463-478

Blomberg SB, Hess GD, Weerapana A (2004b) The macroeconomic consequences of terrorism. J Monet Econ 51(5):1007-1032

Bos CS, Koopman SJ, Ooms M (2012) Long memory with stochastic variance model: a recursive analysis for US inflation. Comput Stat Data Anal 76:144-157

Breitung J, Hassler U (2002) Inference on the cointegration rank in fractionally integrated processes. J Econom 110:167-185

Cohen E, Neal M (2010) Coinciding crises and tourism in contemporary Thailand. Current Issues Tour 13(5):455-475

Demetrescu M, Kuzin V, Hassler U (2008) Long memory testing in the time domain. Econom Theory 24:176-215

Ding Z, Granger CWJ, Engle RF (1993) A long memory property of stock market returns and a new model. J Empir Financ 1:83-106

Dolado JJ, Gonzalo J, Mayoral L (2002) A fractional Dickey-Fuller test for unit roots. Econometrica 70:1963-2006

Edmonds C, Mak J (2005) Terrorism and tourism in the Asia Pacific region: is travel and tourism in a new world after 9/11?. In: Presented at the 2005 apec economic outlook symposium: the economic effects of terrorism and counter-terrorism, June 22-23, 2005. Honolulu, East-West Center

Eugenio-Martín JL, Martín-Morales N, Scarpa R (2004) Tourism and economic growth in Latin American countries: a panel data approach. FEEM Working Paper

Eurostat statistical office of the European union. http://epp.eurostat.ec.europa.eu/portal/page/portal/ eurostat/home

Gil-Alana LA (2008) Fractional integration and structural breaks at unknown periods of time. J Time Ser Anal 29:163-185

Gouveia PM, Guerreiro RF, Rodrigues PM (2013) The world tourism exports cycle. Economic bulletin and financial stability report articles, Banco de Portugal, Economics and Research Department

Granger CWJ, Ding Z (1996) Varieties of long memory models. J Econom 73:61-77

Hall CM (2010) Crisis in tourism events: subjects of crisis in tourism. Current Issues Tour 13(5):401-417

Hassler U, Breitung J (2006) A residual-based LM type test against fractional cointegration. Econom Theory 22:1091-1111

Hassler U, Kokoszka P (2010) Impulse responses of fractionally integrated processes with long memory. Econom Theory 26:1855-1861

Hassler U, Meller B (2014) Detecting multiple breaks in long memory the case of U.S. inflation. Empir Econ 46:653-680

Hassler U, Scheithauer J (2011) Detecting changes from short to long memory. Stat Pap 52:847-870

Hassler U, Rodrigues PMM, Rubia A (2009) Testing for general fractional integration in the time domain. Econom Theory 25:1793-1828

Hassler U, Rodrigues PMM, Rubia A (2014) Persistence in the banking industry: fractional integration and breaks in memory. J Empir Finance 29:95-112

Hassler U, Rodrigues PMM, Rubia A (2016) Quantile regression for long memory testing: a case of realized volatility. J Financ Econom 14(4):693-724

Instituto Nacional de Estatística (2008) Tourism statistics 2008, statistics Portugal, Instituto Nacional de Estatística de Portugal

Instituto Nacional de Estatística (2009) Tourism statistics 2009, statistics Portugal, Instituto Nacional de Estatística de Portugal

Instituto Nacional de Estatística (2010) Tourism statistics 2010, statistics Portugal, Instituto Nacional de Estatística de Portugal

Instituto Nacional de Estatística (2011) Tourism statistics 2011, statistics Portugal, Instituto Nacional de Estatística de Portugal

International Monetary Fund (2010) World economic outlook update, international monetary fund, April. http://www.imf.org

International Monetary Fund (2011) World economic outlook update, international monetary fund, April. http://www.imf.org

International Monetary Fund (2012) Global financial stability report, April (Washington, DC)

Kew H, Harris D (2008) Heteroskedasticity-robust testing for a fractional unit root. Econom Theory $25: 1734-1753$ 
Kumar MS, Okimoto T (2007) Dynamics of persistence in international inflation rates. J Money Credit Bank 39:1457-1479

Marinucci D, Robinson PM (1999) Alternative forms of fractional Brownian motion. J Stat Plan Inference 80:111-122

Martins LF, Rodrigues PMM (2014) Testing for persistence change in fractionally integrated models: an application to world inflation rates. Comput Stat Data Anal 76:502522

Neumayer E (2004) The impact of political violence on tourism: dynamic cross-national estimation. J Conflict Resolut 48(2):259-281

Nielsen M (2004) Efficient inference in multivariate fractionally integrated time series models. Econom J 7:63-97

Nielsen M (2005) Multivariate lagrange multiplier tests for fractional integration. J Financ Econom 3:372398

Papatheodorou A, Rosselló J, Honggen X (2010) Global economic crisis and tourism: consequences and perspectives. J Travel Res 49(1):39-45

Pizam A (2009) The global financial crisis and its impact on the hospitality industry. Int J Hosp Manag 28:301-484

Robinson PM (1994) Efficient tests of nonstationary hypotheses. J Am Stat Assoc 89:1420-1437

Robinson PM (1995) Gaussian semi-parametric estimation of long range dependence. Ann Stat 23:16301661

Robinson PM (2005) Efficiency improvements in inference on stationary and nonstationary fractional time series. Ann Statist 33:1800-1842

Rodrigues PMM, Rubia A, Azevedo JV (2013) Finite sample performance of frequency and time domain tests for seasonal fractional integration. J Stat Comput Simul 83(7):1373-1384

Schwert GW (1989) Why does stock market volatility change over time? J Financ 44:1115-1153

Shimotsu K (2006) Simple (but effective) tests of long memory versus structural breaks. Working Paper, Queen's University

Shimotsu K, Phillips PCB (2005) Exact local Whittle estimation of fractional integration. Ann Stat 33:18901933

Sibbertsen P, Kruse R (2009) Testing for a break in persistence under long-range dependencies. J Time Ser Anal 30:263-285

Smeral E (2009) The impact of the financial and economic crisis on European tourism. J Travel Res 48(1):313

Smeral E (2010) Impacts of the world recession and economic crisis on tourism: forecasts and potential risks. J Travel Res 49:31-38

Song H, Lin S (2010) Impacts of the financial and economic crisis on tourism in Asia. J Travel Res 1:16-30

Tanaka K (1999) The nonstationary fractional unit root. Econom Theory 15:549-582

UNWTO (2013) 2012 International tourism results and prospects for 2013. IGLTA Foundation Symposium February 5, 2013

World Tourism Organization and International Labour Organization (2013) Economic crisis, international tourism decline and its impact on the poor. UNWTO, Madrid

Yamaguchi K (2011) Estimating a change point in the long memory parameter. J Time Ser Anal 32:304-314 